\title{
COMUNICAÇÃO CIENTÍFICA NO BRASIL: CRIAÇÃO E EVOLUÇÃO DA REVISTA ENCONTROS BIBLI
}

\section{COMUNICACIÓN CIENTÍFICA EN BRASIL: CREACIÓN Y EVOLUCIÓN DE LA REVISTA ENCONTROS BIBLI}

Francisco das Chagas de Souza - chagas@cin.ufsc.br

Doutor em Educação pela Universidade Metodista de Piracicaba/SP. Professor do Programa de Pós-Graduação em Ciência da Informação da Universidade Federal de Santa Catarina (UFSC).

\begin{abstract}
Resumo
Este artigo tem como objetivo apresentar uma reflexão sobre a constituição e o desenvolvimento do periódico brasileiro Encontros Bibli, que teve início em 1996, tendo como foco a temática Educação Bibliotecária. Expõe e analisa a trajetória desse veículo de comunicação científica no campo da Ciência da Informação e Biblioteconomia no Brasil e as várias etapas de ajuste ao contexto que envolve esse campo de atividade acadêmica e profissional.
\end{abstract}

Palavras-chave: Educação Bibliotecária; Comunicação Científica; Edição de periódicos. 


\section{INTRODUÇÃO}

A comunicação científica tem como veículo privilegiado o periódico, na medida em que o mesmo difunde predominantemente a produção consolidada pela démarche da pesquisa. Essa démarche ou processo de geração de conhecimento cumpre algumas etapas: a) a verbal, como parte da discussão inicial sobre as conformidades teóricas e metodológicas do trabalho investigativo em si; b) a da formatação escrita das primeiras comunicações, com os resultados preliminares da pesquisa, encaminhados para subsidiar os debates sobre o conhecimento do campo; c) a da transformação dos resultados dos debates realizados em eventos e em outros ambientes em novos textos como acréscimo ou aperfeiçoamento dos primeiros conteúdos escritos, gerando ensaios e artigos. No caso de ensaios, são estruturados em narrativas experimentais pelo menor compromisso com a comprovação dos argumentos. Em sendo artigos, devem submeter-se à característica de produção consolidada e, nesse caso, constituem-se no cerne do conteúdo dos periódicos científicos.

A literatura produzida nos últimos dez anos, no âmbito da comunicação científica ou sobre ela, mostra a ocorrência do crescimento consistente do número de títulos de periódicos científicos (HÖÖK, 1999), demonstrando a amplitude da transformação dos saberes domésticos e de senso comum em saberes especializados, em saberes reificados, para tomar uma acepção de Moscovici. Teorias sociais e psicosociais, de vertente fenomenológica, como o construcionismo (BERGER; LUCKMANN, 1985) e as representações sociais (MOSCOVICl, 2003), ao abordarem a noção de papéis e atribuírem as suas diferenças aos discursos que os constituem, possibilitam associar esses novos campos especializados com a idéia de que expressam o desdobramento de papéis sociais préexistentes em tantos novos papéis quanto sejam necessários às novas demandas dos indivíduos. Seriam assim, representações particulares corelacionadas a domínios específicos de saberes regulados pelos membros de uma comunidade de conhecimento que por eles se constituem, equivalendo à noção de campo, conforme expressa no pensamento sociológico de Bourdieu (2004).

Para a sobrevivência e consolidação dos discursos dessa comunidade, somente a comunicação, incluída a científica, como um estado dinâmico ou um elo que liga os membros das comunidades, constitui o recurso capaz de produzir o mútuo 
reconhecimento e de conferir legitimidade de seu pertencimento ao grupo. Com isso, a comunicação científica está associada aos canais que transferem o conhecimento produzido no âmbito de um determinado grupo cujo saber, particularmente 0 de caráter especializado, é produzido sob determinadas estratégias de construção. Ainda que todo o saber seja originado a partir do vasto universo mental do senso comum, quando sua produção está subordinada à aplicação de métodos, técnicas e instrumentos tidos como sustentadores operacionais de uma estratégia, ou metodologia, globalmente conhecida como ciência, será então um conhecimento científico. Esse conhecimento gerado a partir do emprego da metodologia com que se faz a ciência será 0 resultado da consolidação e comunicação de um jeito de se construir o conhecimento, sendo tipificado por um instrumental próprio, capaz de ser determinado como um produto socialmente constituído: a Ciência.

Um dos instrumentos que permitem a determinado conhecimento especializado ser chamado de ciência e ao ser relacionado à comunicação desse saber lhe confere autoridade é o periódico científico.
A história dos periódicos e, por conseguinte dos periódicos científicos, já foi tratada com certa exaustividade na literatura em Ciência da Informação (BIOJONE, 2003; FACHIN; HILLESHEIM, 2006; MEADOWS, 1999, 2001). Dada a existência dessa história sobre o seu desenvolvimento, também a comunicação científica se transforma em objeto de estudo, particularmente de caráter científico, e sobre ela há uma significativa produção, que a literatura registra às dezenas. Apenas no campo da Ciência da Informação, considerada a Base de dados Library and Information Science Abstrats (LISA) ${ }^{1}$, pode-se encontrar entre os anos de 1997 e 2007 referências de 303 (trezentos e três) trabalhos publicados, conforme busca efetuada em 12 de dezembro de 2007. Outra fonte de dados, constituída em anos mais recentes - OAISTER ${ }^{2}$ registra 397 (trezentos e noventa e sete) referências sobre o tema, em busca realizada nos dias 12 e 13 de dezembro de 2007. Outro tema de interesse mais recente, gerando estudos científicos no âmbito acadêmico relaciona-se às novas possibilidades de comunicação científica. Os estudos sobre ela inserem duas preocupações: a adoção de novas tecnologias voltadas à potencialização da comunicação do conhecimento científico

${ }_{1}^{1}$ http://www.csa.com/factsheets/lisa-set-c.php

2 http://www.oaister.org/ 
e a presença cada vez abundante de novos periódicos gerados em países economicamente periféricos, que nos anos recentes passaram a desenvolver aplicações científicas e também a contribuir na criação de conhecimento científico novo. Essa incidência dá-se em vários campos do conhecimento e se torna visível a partir das novas bases de dados referenciais e bibliográficos construídas no meio digital para promover o registro, controle e difusão do conhecimento cientifico, dentre elas LATINDEX $^{3}, \quad$ DOAJ $^{4}, \quad$ REDALyC $^{5}$, OAISTER, etc.

A complexa teia de recursos e organizações, relacionada ao setor de produção do conhecimento, materializado pela comunicação científica, ao suscitar novas formas de interação e outras possíveis conexões, também permite que se possa refletir sobre o que representa o trabalho de criação e manutenção de periódicos científicos, um tema também identificado na literatura e sobre o qual se encontra uma razoável produção. Em busca feita nos dias 12 e 13 de dezembro de 2007, constatou-se que a Base de dados LISA apontava para 73 (setenta e três) itens publicados entre 1997 a 2007 e a Base OAISTER apontava para 51 (cinqüenta e hum) textos.

\footnotetext{
${ }^{3}$ http://www.latindex.org

4 http://www.doaj.org

$5 \frac{\text { http://redalyc.uaemex.mx }}{}$
}

Neste artigo, abordar-se-á dentro do ambiente editorial brasileiro e nos limites do campo da Ciência da Informação a experiência da constituição e desenvolvimento de um periódico, que contém os traços de um instrumento de comunicação científica neste campo. A partir dessa abordagem buscar-se-á, de modo interpretativo, expor uma apreciação pessoal sobre um processo de trabalho que se desenrola ao longo de onze anos. A fonte dos dados tem caráter bibliográfico e documental, pois se trata de periódico constituído na modalidade eletrônica ou digital. O locus do desenrolar desse processo de análise é a revista Encontros Bibli $^{6}$, editada na Universidade Federal de Santa Catarina, sob a responsabilidade do Departamento de Ciência da Informação e do Programa de Pós-Graduação em Ciência da Informação. Tomada como um caso para ser exposto e analisado em correlação com o tema educação bibliotecária, a reflexão sobre o desenvolvimento da revista Encontros Bibli será feita sob a perspectiva sócio-institucional em coerência com sua trajetória e com as várias circunstâncias que lhe envolvem.

Por tudo isso, o objetivo que se pretende atingir com este artigo, é expor o resultado de um processo de reflexão desenvolvido a partir da perspectiva de

${ }^{6}$ http://www.encontros-bibli.ufsc.br/ 
criação dessa revista em 1996. Em especial, no momento em que, embora implantada no meio digital e eletrônico desde o seu primeiro número, ela está desde o final do ano de 2006, passando pela substituição de sua plataforma de editoração e pela reorganização de seu processo de gestão e produção editorial. Esse processo de migração de plataforma operacional visa ampliar as funcionalidades da publicação dos artigos, bem como melhorar a utilização da revista por seus leitores e sua mais eficaz inserção nos vários canais de intermediação da comunicação científica (indexadores, buscadores de informação, etc.) em âmbito internacional.

\section{ORIGEM E DESENVOLVIMENTO DO PROJETO ENCONTROS BIBLI}

É necessário alertar, já neste momento, que este texto tomará a partir daqui, e em vários instantes, a característica que decorre de ser um discurso realizado sob a perspectiva do idealizador e executor de um determinado projeto editorial e, que por isso, tende a ser majoritariamente uma narrativa, com traços da aplicação de uma metodologia de história de vida institucional. Esse caráter metodológico está vinculado ao processo de reflexão sobre essa experiência e assim já foi referido como parte do objetivo deste texto.

O inicio remoto de Encontros Bibli se imbrica com o doutoramento em Educação de seu proponente. Este doutoramento foi iniciado em agosto de 1992 e concluído, com a defesa de monografia (tese) final, em junho de 1994. Os estudos realizados ao longo dessa formação, sobre a inserção da educação bibliotecária de origem norteamericana, isto é, dos Estados Unidos da América, no Brasil, resultaram na tese de doutorado intitulada Modernização e Biblioteconomia Nova no Brasil, posteriormente publicada como livro, em 2003, com o mesmo título. Desde então, o proponente de Encontros Bibli tinha em mente um norte temático que lhe preocupava, como uma diretriz de pesquisa a ser explorada e aprofundada: a educação bibliotecária, tema que lhe parecia suficientemente adequado para dar início e sustentar a existência de um periódico. A intenção era a de constituir um espaço editorial que permitisse aglutinar ensaios, reflexões e resultados de pesquisas sobre a temática, potencialmente em desenvolvimento no país e, sobretudo, capaz de canalizar os resultados dos esforços que a Associação Brasileira de Ensino em Biblioteconomia e Documentação 
(ABEBD) vinha realizando nos anos noventa do século XX no Brasil.

Em termos materiais, precede à idéia da construção do periódico Encontros Bibli a proposta de criação de uma revista de Biblioteconomia no Departamento de Biblioteconomia e Documentação da Universidade Federal de Santa Catarina (BDC/UFSC), sem um foco temático dirigido. Essa proposta, feita em 1995, e apresentada ao Departamento, não foi acolhida na oportunidade.

Num momento seguinte, já no começo de 1996, a idéia foi um pouco mais amadurecida, levando ao início de um projeto, que hoje poderia ser tomado como uma ousadia pessoal, sem financiamento de qualquer fonte, inteiramente a expensas de seu proponente, até pelo fato de ser algo experimental, com reprodução em pequena tiragem a ser dirigida para os/as colegas do Departamento de Biblioteconomia e Documentação, para as escolas de Biblioteconomia do país e para algumas entidades desse campo profissional. E assim começou também como uma produção pessoal, isto é, na qual seu proponente poderia, e o fez, colocar as idéias que concebia em torno da educação bibliotecária. E propunha que isso seria algo a ser submetido à discussão e crítica dos pares, uma vez por semestre.

A hoje revista Encontros Bibli iniciou sua trajetória editorial em maio de 1996, com a publicação do primeiro número. Desde a primeira edição foi disponibilizada integralmente na Web, embora dos primeiros quatro números tenham sido produzidas simultaneamente versões em papel, com a finalidade de divulgação junto aos Cursos de Biblioteconomia no país, Associações Profissionais, Acadêmicas e Científicas relacionadas aos campos de interesse cobertos pela revista.

A idéia inicial era a de que se trataria de um periódico voltado para a abordagem das questões relativas à educação bibliotecária. Em nota preliminar, que se encontra no número inicial da revista, consta a afirmação de que "[...] esta é uma experiência nova e particular, com a qual desejo estar abrindo um espaço de debate com a [o]s colegas envolvidos em todo o País com a discussão em torno de algumas questões do ensino de Biblioteconomia e, em especial, com a questão do Currículo. De outro lado, poderia ser uma oportunidade de se estar resgatando e fortalecendo formas de ampliação do diálogo acadêmico que, embora esteja crescendo em vários outros campos profissionais, não acontece com a mesma intensidade 
na Biblioteconomia. Assim, o que se deseja com esta mensagem que está sendo remetida aos Cursos de Biblioteconomia existentes no País, é estar apostando que -- para além dos eventos técnico-científicos e das parcas publicações, tanto em formato livro, quanto em formato seriado, aí inserida a publicação periódica, -- ainda há gente nesses cursos. Gente no sentido de que pensa como indivíduo e cidadão integrado na sociedade, sendo, portanto, responsável pelo fazer das profissões e não se deixando ser escravo e submisso às profissões. Sendo capaz de perceber que há uma ética nas relações humanas e que, por mais boa vontade que se tenha, não dá para deixar simplesmente nas mãos das profissões toda a tomada de decisão sobre o que é bom para o utilizador. Ou seja, é preciso se discutir se a regência da relação leitorbibliotecário pode se dar por satisfeita com a aplicação do "Código de Ética" que, se sabe, sustenta-se no que é pensado pela categoria profissional e que é, por isto, um Código Moral”.

Aquele número contou com apenas um artigo de autoria do proponente e se intitulava "Um Currículo para o Curso de Biblioteconomia".

No segundo número, lançado em setembro de 1996, foi mantida a linha temática e, novamente, foi apresentado um único artigo de autoria do proponente de Encontros Bibli, intitulado "Os Paradigmas da Biblioteconomia e suas implicações no Ensino desta Ciência". Para essa edição não foi apresentada qualquer nota precedendo o texto, pois continuava presente a idéia de ser um espaço editorial para $\mathrm{o}$ debate da Educação Bibliotecária.

Um acontecimento que muito contribuiu para dar permanência à revista ocorreu nesse momento. Por ocasião da entrega de um exemplar a cada colega do Departamento de Biblioteconomia e Documentação da Universidade Federal de Santa Catarina (BDC/UFSC), a Professora Ursula Blattmann, colega de Departamento, já há muito envolvida com a inserção do conhecimento de informática nas disciplinas e na grade curricular do Curso de Graduação em Biblioteconomia e, sobretudo, pelo esforço em utilizar o espaço da web com produtos então em desenvolvimento utilizando o html, propôs-se a converter o material dos dois números já disponíveis para este formato e editá-los e publicálos com o recurso da editoração em meio digital, utilizando como servidor de páginas o equipamento do Centro de Ciências da Educação ao qual o BDC estava vinculado. A partir de então, Encontros Bibli passou a integrar 0 
elenco de periódicos em arquivo aberto com acesso on-line.

$\mathrm{Na}$ continuação do trabalho, o número três, de abril de 1997, não divergiu quanto à temática central, autoria e número de artigos dos que o precederam. Aí, uma vez mais, estava um único artigo, com o título: "O Ensino de Biblioteconomia no Brasil: questões acerca do modelo Deweyano".

A partir do número quatro, de setembro de 1997, há indícios formais no sentido da ampliação dos horizontes e do caminho para a conquista de uma consolidação, que se manifesta no expediente do Encontros Bibli, o qual vincula o periódico ao Departamento de Biblioteconomia e Documentação da Universidade Federal de Santa Catarina. Este número traz um subtítulo: "Revista de pesquisa e opinião sobre a educação biblioteconômica no Brasil" que, confirma sua linha temática; apresenta a sua primeira Comissão Editorial, formada, então, pelas Professoras Maria del Carmen Rivera Bohn, Maria Margarete Sell da Mata, Neide Caciatori Brighenti e Ursula Blattmann, e a inclusão de seu proponente como Coordenador da Comissão, e traz a primeira colaboração externa, o artigo "A Criação e o Reconhecimento do Curso de Biblioteconomia da UFES", de autoria das Professoras Dulcinéa Sarmento
Rosemberg e Lucia Helena Miranda Corrêa, docentes da Universidade Federal do Espírito Santo.

A nota preliminar apresentada naquele fascículo dizia "É com satisfação que nesta edição do Encontros Bibli, a de número 4, iniciamos com duas novidades. A primeira é a de termos constituído uma Comissão Editorial, que torna o periódico apto a receber e analisar as contribuições intelectuais de nossa(o)s colegas que se disponham a pensar e discutir publicamente a Educação Biblioteconômica no Brasil. A segunda novidade é precisamente a de inaugurarmos a publicação de trabalhos externos. Com isso, queremos convidar a quem se interessar por esta temática que enviem suas contribuições para o Encontros Bibli. Isso, certamente, nos tornará interlocutores mais comprometidos com esta questão de fundamental importância para o incremento da Biblioteconomia e Ciência da Informação no País.”.

Então, a partir dessa manifestação, ficou consignada a expectativa da temática Educação Bibliotecária, como o interesse de Encontros Bibli.

Apesar da abertura e da extensão do convite para os calaboradores, o número cinco, de abril de 1998, contou ainda com apenas um artigo, das Professoras Maria del Carmen Rivera 
Bohn e Neide Caciatori Brighenti, com o título "Produção de material instrucional para o ensino de Fontes de Informação" e com uma nota do Coordenador Editorial que dizia: "Nesta 5 edição do Encontros Bibli, agradecemos a acolhida de todos, destacando as manifestações de apoio carinhosamente dirigidas à Comissão. Face a isso, continuamos a insistir que este é um espaço para troca e veiculação das idéias em torno da Educação em Biblioteconomia no Brasil. É por isso que esperamos sempre poder contar com a colaboração dos/das Professores/as de Biblioteconomia e Ciência da Informação que trabalham neste imenso Brasil. O número 5 traz um artigo que resultou de pesquisa em ensino realizada por Professoras do Departamento de Biblioteconomia e Documentação da Universidade Federal de Santa Catarina (BDC/UFSC) - sobre uma área fundamental para a formação e futura atuação dos profissionais da área de informação".

O número seis, de setembro de 1998, trouxe várias modificações, a iniciar-se com o subtítulo do periódico, dando uma nova dimensão para sua linha temática "revista de Biblioteconomia e Ciência da Informação". Claramente, a realidade da ausência de mais colaboradores sobre a temática até então eleita mostrava não haver ainda no espaço editorial brasileiro lugar para um periódico especializado em Educação Bibliotecária. Esse tema estaria destinado a integrar-se em periódicos com linha editorial mais ampla em Biblioteconomia e Ciência da Informação. Neste número, inauguram-se as seções permanentes: Editorial e Artigos, com o fascículo trazendo cinco colaborações. Pela primeira vez, registra-se 0 recebimento de material impresso de outra instituição encaminhado à revista para divulgação ou resenha. O editorial desta edição ressalta a origem do material que foi selecionado pela Comissão Editorial. Dizia-se, então "Constitui importante experiência aquela que converge para a reunião dos discursos de um grupo de interesse em certo momento. E um periódico, seja impresso com tinta e papel, convencionalmente, seja publicado em meio eletrônico como este, é uma reunião de discursos. O que particulariza esta $6^{a}$. edição do Encontros Bibli (EB) é o fato de que resulta de duas reuniões de discursos. A primeira foi conseqüência do XXI ENCONTRO NACIONAL DE ESTUDANTES DE BIBLIOTECONOMIA E DOCUMENTAÇÃO que ocorreu na cidade de Florianópolis, no final do mês de julho de 1998 e a segunda - que é esta - tomou a primeira como sua base, selecionando de quase duas dezenas de textos apresentados os cinco que 
compõem esta edição. Isso não retira o mérito de outros trabalhos ali expostos, alguns deles já comprometidos com a oferta de publicação em outros veículos. A temática que se traz nesta edição dirige-se ao processo de interação do acadêmico de biblioteconomia brasileiro com a leitura, o trabalho profissional na educação fundamental, as novas tendências do mercado atual, o currículo de bacharelado e o movimento estudantil em biblioteconomia. É, portanto, um número do Encontros Bibli (EB) rico em seu conteúdo e que, com felicidade, inaugura uma nova fase deste periódico eletrônico. Também é marcante para a equipe do EB o fato de que, oficialmente, passa a ser, desde agosto deste ano, um projeto de extensão do Departamento de Biblioteconomia e Documentação da UFSC. Igualmente marcante é o acréscimo à Comissão Editorial da Profa. Dra. Eliany Alvarenga de Araújo, do Departamento de Biblioteconomia e Documentação da Universidade Federal da Paraíba."

O número sete, de abril de 1999, foi apresentado sob nova coordenação editorial. A editoria passou ao encargo da Profa. Miriam Vieira da Cunha, nova integrante e coordenadora da Comissão Editorial e Editora do periódico. Também nesta edição pela primeira vez foi publicada uma resenha de livro. Uma novidade no expediente é que a responsabilidade institucional passou ao Departamento de Ciência da Informação. Até a edição anterior mencionava-se o Departamento de Biblioteconomia e Documentação, que era a designação anterior do Departamento, superada pela aprovação por parte da UFSC da adoção de novo nome.

O número oito, de setembro de 1999, traz como novidade a criação de uma seção intitulada "contribuições de estudantes". O tom do editorial desse número confirma que Encontros Bibli continuava como um espaço editorial em que a discussão das questões da Educação Bibliotecária continuavam a ter viva presença.

A edição de número nove, de junho de 2000, além da presença de contribuições de pesquisadores de outras Instituições de Ensino Superior (IES), trouxe o ISSN, instrumento de ampliação da inserção da revista em espaços mais amplos do mundo da produção e difusão de periódicos e inaugurou um acesso ao "webmaster".

O número dez, de outubro de 2000 , refletia a continua maturação de sua presença no cenário editorial da área e embora apresentasse apenas três artigos, 0 editorial registrava afirmativamente o reconhecimento do periódico por uma comunidade mais 
ampla ao dizer: "É com satisfação que informamos que, a partir deste número, nossa Comissão Editorial conta com a colaboração dos colegas, Elsa Barber, da Universidad de Buenos Aires, Mario Barité, da Universidad de la Republica do Uruguai, Marta Valentim da Universidade Estadual de Londrina e José Augusto Guimarães da Universidade Estadual Paulista. Neste sentido pretendemos garantir uma maior circulação de idéias e de competências para avaliação dos trabalhos e uma maior visibilidade a nossa revista. Encontros Bibli objetiva ser um canal de comunicação aberto, ágil e estimulador da disseminação de idéias e debates na área de Biblioteconomia e Ciência da Informação. As contribuições em forma de artigos inéditos, relatos de experiências e resenhas fazem parte da produção editorial que se pretende veicular nesta revista."

O último parágrafo acima reorienta Encontros Bibli para a produção de conhecimento na área, sem oferecer a especifidade de espaço editorial para grupo, como anteriormente havia afirmado com relação à contribuição de estudantes. Essa reorientação já caminhava no sentido de Encontros Bibli se apresentar como um veículo mais comprometido com a veiculação da produção científica.
O número onze, de junho de 2001, apesar do editorial apresentado na edição anterior, traz uma contribuição na seção "contribuições de estudantes" e, pela primeira vez, traz, na seção artigos, um texto em língua espanhola oriundo de contribuição vinda do exterior.

O número doze, de dezembro de 2001, abre uma seção "comunicação de pesquisa", com texto em espanhol, e traz novamente a seção "contribuições de estudantes".

O número treze, de maio de 2002 , trouxe novo texto em língua espanhola. $A$ partir desse momento o Prof. Angel Godoy começa a participar da Comissão Editorial. Ocupa a posição aberta com a saída da Professora Ursula Blattmann, que investe mais de seu tempo na sua formação Doutoral, então, em andamento.

A partir da edição de número quatorze, de outubro de 2002, a Professora Miriam Cunha assumiu a Coordenação do curso de Graduação em Biblioteconomia da UFSC e o proponente de Encontros Bibli retornou para a Coordenação Editorial e Editoria da revista. Isso coincidiu com a implantação de algumas novidades e mudanças estruturais que vinham sendo discutidas no âmbito da Comissão Editorial. Essas mudanças são explicadas no editorial desse número: "A Ciência da Informação 
e a Biblioteconomia realizadas no Brasil e na América do Sul, por seus corpos profissionais, suas estruturas operacionais e seu universo sensível e inteligente, estão vivendo neste ano de 2002 uma intensa movimentação acadêmica e profissional. Demonstrativo disto é o número de eventos profissionais, científicos e acadêmicos de grande e médio porte, executados no Brasil como o XX Congresso Brasileiro de Biblioteconomia e Documentação (CBBD), o XII Seminário Nacional de Bibliotecas Universitárias (SNBU), o Encontro de Diretores e Docentes das Escolas de Biblioteconomia e Ciência da Informação do Mercosul, além dos eventos estaduais cobrindo temas de interesse multivariado que atendem às demandas locais de aperfeiçoamento e compreensão da realidade em volta. Também se exibe esse esforço através da publicação de vários livros, alguns dos quais anunciados nesta 14a. edição deste Encontros Bibli. Ouvimos falar de vários outros livros, mas deles não recebemos comunicação ou exemplares dos autores com vistas a resenha e/ou anúncio, o que esperamos possa ser feito na próxima edição. No que tange a edições periódicas e seriadas impressas e em linha há também novidades sendo anunciadas no Brasil como Em questão da Faculdade de Biblioteconomia e Comunicação da Universidade Federal do Rio Grande do Sul (FABICO/UFRGS) e Teoria \& Crítica da Associação Brasileira de Ensino de Ciência da Informação (ABECIN). O fato de nos limitarmos a apontar o quadro brasileiro tem dois significados: a) obtivemos informações mais prontamente sobre esses fatos; e b) estimular a que nossos colegas dos países vizinhos, dentre os quais temos alguns membros em nosso Conselho Editorial, nos remetam notícias de suas produções e publicações e originais de artigos para que se mantenha, fortaleça e efetive, prioritariamente, o caráter regional deste espaço de Encontro com a inteligência Bibliotecária e de Informação na América do Sul e Central, sem exclusão de outras regiões do mundo. De outro lado, a partir desta edição passa a ser caracterizada a existência de uma Comissão Editorial, isto é, o grupo executivo deste periódico e de um Conselho Editorial permanente, ou seja, nossos conselheiros e avaliadores externos. Por ser o Encontros Bibli um periódico com avaliação por pares é fundamental que se tenha a clareza da distribuição de nossos papéis. Naturalmente, continuaremos a pedir a colaboração de pareceres ad hoc, contando para isso com a participação de outros/as colegas que, compreendendo a importância deste empreendimento, têm colaborado com a construção deste Encontros. 
A partir desse número quatorze, Encontros Bibli adota o subtítulo "revista eletrônica de biblioteconomia e ciência da informação" que permanece e passa a informar na página do Sumário todos os consultores ad hoc e os membros da Comissão e do Conselho Editorial que emitiram pareceres sobre os originais submetidos pelos autores e também passa a contar com novo design, contendo uma capa e um sumário que remete inicialmente para a última edição publicada.

Nessa altura da história de Encontros Bibli, havia um evidente sentimento de que se estava caminhando para a consolidação do projeto. A partir do número quinze, do primeiro semestre de 2003, por decisão da Comissão Editorial, passou-se a expressar a periodicidade da revista, sobretudo para configurar o fato da semestralidade, mas também para evitar uma característica não desejada do periódico parecer contar com uma periodicidade irregular. Além dessa mudança, essa edição trazia um texto do Coordenador Editorial intitulado "Projeto Editorial do Encontros Bibli", que expunha todo o processo de trabalho adotado para a editoria, tendo-se como expectativa sua utilidade tanto para os colaboradores, quanto para a Comissão Editorial.
O número 16 de Encontros Bibli, lançado no segundo semestre de 2003, deu um novo passo institucional ao periódico, fortalecendo-o, que foi o de estar vinculado não somente ao Departamento de Ciência da Informação da Universidade Federal de Santa Catarina (CIN/UFSC), mas por vincularse também ao Programa de PósGraduação em Ciência da Informação (PGCIN). Esta foi uma decisão estratégica da Comissão Editorial de Encontros Bibli e acatada pelos Colegiados tanto do Departamento quanto do Programa de Pós-Graduação. A idéia era a de que esta relação daria mais respaldo ao intercâmbio tanto no âmbito do ensino e pesquisa que envolvem o Departamento e o Programa, quanto à publicação de outros veículos científicos ligados à área da Ciência da Informação. Essa iniciativa coincidiu com o período de implantação do PGCIN, iniciada em junho de 2003.

Por essa mesma época, Encontros Bibli começou a contar com uma fonte de difusão externa. Em dezembro de 2002, recebeu convite para dispor on-line o seu conteúdo na Red de Revistas Científicas de América Latina y El Caribe (Red ALyC), então uma iniciativa de pesquisadores da Universidad Autónoma del Estado de México. 
Como resultado desse convite, a partir do número dezesseis, do segundo semestre de 2003, Encontros Bibli foi integrada à Rede AlyC, com todo o seu conteúdo transposto para aquela fonte, de modo que a consulta e uso de Encontros Bibli passou a ter um segundo servidor de páginas. Depois do ingresso na Red AlyC a etapa seguinte foi a indexação no LATINDEX, o que se deu a partir do número dezessete, do primeiro semestre de 2004.

Desnecessário é dizer que para Encontros Bibli, havia um significado importante em participar do LATINDEX, por algumas razões: ampliar sua difusão integrar-se em rede de revistas científicas de repercussão internacional e adotar parâmetros de qualidade mais consagrados e o LATINDEX respondia e responde a isso, quando se auto-define como

producto de la cooperación de una red de instituciones que funcionan de manera coordinada para reunir y diseminar información bibliográfica sobre las publicaciones científicas seriadas producidas en la región e [...] sirve también a la comunidad internacional (organismos y/o personas) interesada en los contenidos, temas y acciones relacionados con la ciencia y la información científica en la región (LATINDEX. 2008, p.1).

A Cobertura do LATINDEX em termos Geográficos alcança a "América Latina, el Caribe, España y Portugal"; em termos Temáticos considera "todas las publicaciones seriadas en las disciplinas de las ciencias exactas, naturales, sociales y humanas" e em termos de Idioma acolhe "cualquier idioma empleado en la región" (LATINDEX. 2008, p.1).

Ainda em relação à convergência de fatores positivos para a editoração científica no Brasil, no ano de 2003, a Coordenação de Aperfeiçoamento de Pessoal de Nível Superior (CAPES) ${ }^{7}$ instituiu o indicador Qualis. Segundo o site dessa Agência "Qualis é o resultado do processo de classificação dos veículos utilizados pelos programas de pós-graduação para a divulgação da produção intelectual de seus docentes e alunos [...] e baseia-se nas informações fornecidas pelos programas pelo Coleta de Dados." (CAPES, 2008, p.1). A partir disso, as Comissões, por área de avaliação da CAPES desenvolveram critérios para construir as listas de periódicos com visibilidade em cada área. No caso da Área de Ciências Sociais Aplicadas I, que se constitui por Comunicação e Ciência da Informação, foram definidos os critérios de avaliação dos periódicos e a lista resultante, divulgada em 2003, tomou como ano de referência o período 2001-2002. Então, o QUALIS A Nacional atribuído a Encontros Bibli, representa sua resposta aos

\footnotetext{
${ }^{7}$ http://www.capes.gov.br/
} 
Critérios de Qualificação adotados para os Periódicos Científicos dessa Área.

Assim, o ingresso de Encontros Bibli no Qualis decorreu de ser capaz de corresponder a critérios formais e de mérito, próprios da produção e difusão do conhecimento científico. Por conta de sua avaliação no Qualis, Encontros Bibli responde aos critérios de inserção no Portal de Periódicos Capes, a grande biblioteca acadêmica on-line da América Latina, onde se encontra desde 2004.

Num grande esforço editorial, voltado a criar um diferencial possível na comunicação em Ciência da Informação no Brasil, no ano de 2004, paralelamente aos números dezessete e dezoito, deu-se início, como atividade experimental, para testar uma futura modificação de periodicidade, à edição de números monográficos especiais. Através dessa iniciativa, convidam-se membros do Conselho Editorial ou não para, na condição de editores convidados, coordenarem a edição de um tema a partir da reunião de vários autores que pesquisam sobre a matéria. A edição do primeiro semestre de 2004 foi coordenada pela Profa. Marta Valentim, então docente na Universidade Estadual de Londrina, e versou sobre Inteligência Competitiva. A edição do segundo semestre foi coordenada pelas Professoras Patrícia Zeni Marchiori,
Sônia Maria Breda e Ligia Bartz Kraemer, da Universidade Federal do Paraná e tratou do tema Metodologias para a gestão da informação. Nos anos subseqüentes, novas edições monográficas foram publicadas.

\section{AS NOVAS ETAPAS}

A partir de 2005 Encontros Bibli vem buscando ampliar ainda mais a sua visibilidade. Dentre as ações encetadas estão o esforço de inserção em novos mecanismos de difusão, a adoção de nova plataforma de editoração e gestão editorial, o envolvimento na organização e realização de evento que trate o tema Comunicação Científica, a estimulação para que se difunda o uso pelas revistas científicas catarinenses do Sistema de Editoração Eletrônica, distribuído no Brasil pelo Instituto Brasileiro de Informação em Ciência e Tecnologia (IBICT), fortalecendo assim as iniciativas internacionais dirigidas ao ACESSO LIVRE à produção do conhecimento.

Em conseqüência disso, passou a ser indexada e a ter seu conteúdo também localizável a partir do Directory of Open Acess Journal (DOAJ), empreendimento da Biblioteca da Lund University, Suécia. Através desse mecanismo, todos os artigos de todas as suas edições podem ser localizados e baixados pelos usuários da revista. 
Em 2005 promoveu o primeiro treinamento, na região sul, em Florianópolis, de uso do Sistema Eletrônico de Editoração de Revistas $(\text { SEER) })^{8}$. Para isso, contou com apoio da UFSC e do IBICT, com a presença de técnicos dessa instituição e contando com a participação de representantes, editores ou técnicos, de periódicos acadêmicos de Instituições de Ensino Superior (IES) catarinenses.

Em maio de 2006, Encontros Bibli promoveu o Simpósio de Comunicação Científica na UFSC, cuja programação versou sobre o tema Desafios da Inclusão Digital contou com as presenças, dentre outros debatedores, de Suzana Mueller (UnB), Hélio Kuramoto (IBICT) e Regina de Castro (BIREME).

Dessa maneira, Encontros Bibli tem se posicionado como uma revista plural, de conteúdo diversificado, contando com alguns artigos sobre a educação bibliotecária. É forçoso reconhecer que não é possível publicar conteúdos que não são produzidos. Mesmo em âmbito internacional, educação bibliotecária é um tema cuja produção, identificada em busca realizada na Base LISA em 12 de dezembro de 2007, contada de 1997 a 2007, totalizava 49 (quarenta e nove) trabalhos, quando utilizado o cabeçalho "Librarianship education".
Assim, mantido o enfoque na diversidade de conteúdo, as edições especiais monográficas ao tratarem de objetos do campo da Ciência da Informação, articulam temas consoantes com os interesses de um leitorado mais amplo, respondendo a todas as expectativas, julgadas relevantes por sua Comissão Editorial. Dentre estes a edição monográfica especial de 2007, coordenada por Hélio Kuramoto (IBICT) e Lígia Café (UFSC), versou sobre Tecnologia da informação e arquivos abertos e inseriu entrevista com Stevan Harnad um dos mais influentes estudiosos do assunto.

\section{O OLHAR EXTERNO}

A Comissão Editorial de Encontros Bibli sempre esteve muito atenta às avaliações recebidas, tanto sobre o seu conteúdo, quanto sobre sua forma e funcionalidades, seja através de manifestações diretas dos leitores e usuários, seja pela apreciação crítica consolidada em artigos de periódicos ou em trabalhos de eventos científicos da Ciência da Informação (GALVÃO, 2006; LEITE; MÁRDERO ARELLANO; MORENO, 2006; SILVA; PINHEIRO; MENEZES, 2005). Essas manifestações e análises representam uma contribuição espontânea da comunidade acadêmica e profissional da Ciência da Informação.

${ }^{8}$ http://www.ibict.br/secao.php?cat=SEER 
Seguramente, resultam de exame detido de seu (s) autor (es) a partir de aspectos que não foram até então pensados, ou de itens que por diversas razões não puderam ser captados, mas que asseguram a melhoria e ampliação do diálogo com o usuário ou leitor da revista e que contribuem para a expansão de sua qualidade.

\section{CONSIDERAÇÕES FINAIS}

Pode-se afirmar que Encontros Bibli é produto de uma ousadia e reflete 0 espaço, tempo e condições que asseguram a sua criação e permanência. Trata-se de um produto do pensamento e ação de quem está presente no campo da ciência da informação em particular, sob as condições materiais que encorpam um projeto originado na universidade e com os meios que esta pode oferecer. Ademais, desde o seu começo, reflete um projeto que visa fomentar a discussão da Biblioteconomia e Ciência da Informação.

De início, visava incorporar e difundir o discurso pensado em torno do tema Educação Bibliotecária, o que o tempo frustrou e mostrou a limitada produção nesta temática. Surgida na década dos anos 1990, em que a Associação Brasileira de Ensino de Biblioteconomia e Documentação (ABEBD) promoveu várias ações de discussão e tentou fomentar a inovação curricular e a integração das escolas de Biblioteconomia no Brasil e na América Latina, Encontros Bibli não contou em suas páginas com muito mais contribuições intelectuais que poderiam ter sido geradas nessa década e na década seguinte sobre o tema. Mas essa produção não foi enviada para publicação, porque se foi esboçada permaneceu nas gavetas de seus autores.

Assim, pode-se pensar que Encontros Bibli, como projeto editorial de periódico científico, só pode existir na medida em que flexibilizou sua linha temática inicialmente pretendida, incorporando o leque de assuntos e interesses da Ciência da Informação e Biblioteconomia. Isso poderia apontar para o fato de que o tema EDUCAÇÃO BIBLIOTECÁRIA propicia pouca COMUNICAÇÃO CIENTÍFICA NO BRASIL. Ao menos, a trajetória da revista Encontros Bibli não pode ser feita com essa única temática. Tal fato, seguramente, aponta para a necessidade de se debater, muito mais do que fez a ABEBD e hoje faz a ABECIN sobre a Educação e seus objetos de estudo no ambiente em que se desenvolve a capacitação de bacharéis, mestres e doutores no Brasil. 
De outro lado, se para existir Encontros Bibli ajustou-se tematicamente ao meio próximo, também vem buscando incorporar progressivamente os avanços que a tecnologia dispõe para sua gestão e produção. Isso implica o diálogo com novos recursos de inteligência, mas, sobretudo implica iniciativas políticas no sentido de estar aberta às manifestações e críticas de seus leitores. São os seus leitores, os seus colaboradores como autores e pareceristas e as organizações que voluntariamente replicam suas páginas, difundindo mais amplamente a revista, que sustentam Encontros Bibli, como um projeto situado no universo da Comunicação Científica, com a expectativa de ter um espaço editorial também para 0 tema Educação Bibliotecária.

\section{REFERÊNCIAS}

BERGER, P. I.; LUCKMANN, Th. A construção social da realidade: tratado de Sociologia do conhecimento. 6. ed. Petrópolis: Vozes, 1985.

BIOJONE, Mariana Rocha. Os periódicos científicos na comunicação da ciência. São Paulo: Educ/Fapesp, 2003.

BOURDIEU, Pierre. Os usos sociais da ciência: por uma sociologia clínica no campo científico. São Paulo: Unesp, 2004.

CAPES. Classificação de periódicos, anais, revistas e jornais. Disponível em: <http://qualis.capes.gov.br/webqualis/>. Acesso em: 18 ago. 2008.

FACHIN, Gleisy Regina B.; HILLESHEIM, Araci I. de Andrade. Periódico científico: padronização e organização.

Florianópolis: Ed. UFSC, 2006.

GALVÃO, Rodrigo. Avaliação ergonômica do periódico científico eletrônico Encontros Bibli. In: SEMINÁRIO NACIONAL DE BIBLIOTECAS UNIVERSITÁRIAS, 14., Salvador. Anais...Salvador, 2006. CD-ROM.

HÖÖK, Olle. Scientific communications: history, electronic journals and impact factors. Journal of Rehabilitation Medicine, v. 31, n. 1, p. 3-7, Jan. 1999. Disponível em: <http://www.informaworld. com/smpp/content $\sim$ content $=a 713603321$ $\sim \mathrm{db}=a$ ll $>$. Acesso em: $11 \mathrm{dez} .2007$.

LATINDEX. Qué es latindex. Disponível em: < http://www.latindex.org/latindex/ busquedas1/latin.html>. Acesso em: 18 agos. 2008.

LEITE, Fernando César Lima; MÁRDERO ARELLANO, Miguel Angel; MORENO, Fernanda Passini. Acesso livre a publicações e repositórios digitais em Ciência da Informação no Brasil. Perspectivas em Ciência da Informação, v. 11, n. 1, jan./abr. 2006.

MEADOWS, Arthur Jack. A comunicação científica. Brasília: Briquet de Lemos, 1999.

Os periódicos científicos e a transição do meio impresso para o eletrônico. Revista de Biblioteconomia de Brasília, Brasília, v. 25, n. 1, p. 5-14, jan./jun. 2001.

MOSCOVICl, S. Representações sociais: investigações em Psicologia Social. Petrópolis: Vozes, 2003.

SILVA, Edna; PINHEIRO, Liliane; MENEZES, Estera. Revista Encontros Bibli como veículo de disseminação do 
conhecimento no Brasil. Encontros Bibli: Revista Eletrônica de Biblioteconomia e Ciência da Informação, n. 19, 1. sem. 2005. <http://www.periodicos.ufsc.br/ index.php/eb/article/view/154/202>.

Acesso em: 11 dez.2007.

\section{Title}

Scientific communication in Brazil: the creation and evolution of the Encontros Bibli journal

\section{Abstract}

This paper aims to present a reflection on the establishment and development of the Brazilian Journal Encontros Bibli, which began in 1996, with a focus on the Librarianship Education theme. It presents the trajectory of this journal as a scientific communication mean for Information Science and Librarianship areas in Brazil and also analyzes its various stages of adjustment to the context which involves this academic and professional activity field.

\section{Keywords}

Librarianship Education; Scientific communication; Journals' Publishing.

\section{Titulo}

Comunicación científica en Brasil: creación y evolución de la revista Encontros Bibli

\section{Resumen}

Este trabajo tiene como objetivo presentar una reflexión sobre la creación y el desarrollo de la revista brasileña Encontros Bibli, que se inició en 1996, con un enfoque en el tema Educación Bibliotecológica. En él se presenta y analiza la trayectoria de esa revista de comunicación científica en el campo de la Bibliotecología y Ciencia de la Información en Brasil en diversas etapas de su adaptación al contexto.

\section{Palabras clave}

Educación bibliotecológica; comunicación científica; edición de revistas.

Recebido em: 27/02/2008

Aceito em: 28/04/2008 